\title{
Comparing the Prevalence of Postoperative Complications in Groups of Patients Followed Up in the Recovery Room with and without the Use of the Modified Aldrete's Scoring System (MASS): A Retrospective Study
}

öz

Amaç: Bu çalışmayla uyandırma odasında skorlama sistemini kullanmanın, uyandırma odasında takip edilen hastalarda postoperatif komplikasyon gelişmesi üzerine etkisini retrospektif olarak göstermeyi amaçladık.

Yöntem: Hastanemizde 2010-2017 yılları arasında opere edilmis hasta dosyalarını inceledik. Anestezi sonrası uyandırma odasında Modifiye Aldrete Skorlama Sistemi (MASS) ile takip edilen (MASG) ve skorlama sistemi kullanılmadan (KG) takip edilen hastalarda uyandırma odasında ve erken dönemde serviste gelişen komplikasyonlar kayıt altına alındı ve istatistiksel analiz için Statistic 13.3 programı kullanıldı.

Bulgular: Uyandırma odasında kalış süresi MASG'da KG'a göre uzundu. Her 2 grupta minör komplikasyon oranı birbirine yakın olarak saptandı. Kontrol grubunda 1 hastada majör komplikasyon olarak kardiyopulmoner resusitasyona yanıt veren kardiyak arrest geliştiği saptandı.

Tartışma ve Sonuç: Uyandırma odasında, skorlama sistemi kullanılmayan hastalarda skorlama sistemi kullanılan hastalara göre daha ciddi komplikasyon geliştiğini saptadık. Hastaların servise aktarılmaları sırasındaki hasta güvenliği; anestezi uyandırma odalarında gelişmiş bir altyapıya sahip olmak, eğitimli sağlık personeli istihdam etmek ve MASS gibi algoritmalar kullanmaya bağlıdır.

Anahtar kelimeler: Uyandırma odası, MASS, komplikasyon

\section{ABSTRACT}

Objective: This retrospective study aims to demonstrate whether using scoring systems effects postoperative complications of patients in the recovery room as well as its contribution to patients' safety

Method: We examined files of patients operated in our Hospital between 2010 and 2017. In the recovery room after anesthesia, complications developed in the recovery room and in the early period were recorded in patients who were followed up by the Modified Aldrete Scoring System (MASS) (MASG) and without using the scoring system (CG). We used Statistica 13.3 program for statistical analyses.

Results: The duration of stay in the recovery room was longer in MASG than CG. The minor complication rate was close in both groups. In the control group, one patient had a cardiac arrest, as a major complication, which responded to cardiopulmonary resuscitation.

Conclusions: We determined that more serious complication developed in patients for whom the scoring system was not used in the recovery room than patients followed up with the scoring system. Safety of patients during their transfer to the service depends on having an advanced infrastructure in anesthesia recovery rooms, employing trained health personnel and using algorithms such as MASS.
Received: 11 March 2020

Accepted: 05 June 2020

Publication date: 30 July 2020

Cite as: Özmen H, Aydınlı B, Titiz L, Derici D. Uyandırma odasında hasta takibinde modifiye Aldrete skorlama sistemi (MASS) ile çalışmanın postoperatif komplikasyon görülme sıklığı üzerine etkisi: Retrospektif Çalıșma. JARSS 2020;28(3):188-93.

Harun Özmen

Sağlık Bakanlığı Mersin Şehir Eğitim ve Araştirma Hastanesi, Anesteziyoloji ve Reanimasyon Kliniği, Mersin, Türkiye hrnozmn@gmail.com ORCID: 0000-0002-0392-9099

B. Aydınlı 0000-0002-7062-3137

L. Titiz 0000-0001-6142-1552 Sağlık Bakanlığı Mersin Şehir

Eğitim ve Araşttrma Hastanesi, Anesteziyoloji ve Reanimasyon Kliniği, Mersin, Türkiye

D. Derici 0000-0001-7709-6133 Mersin Üniversitesi, Tıp Fakültesi Biyoistatistik Bilim Dal,, Mersin, Türkiye

Keywords: Recovery room, MASS, complication 
H. Özmen ve ark., Uyandırma Odasında Hasta Takibinde Modifiye Alderete Skorlama Sistemi (MASS) ile Çalışmanın Postoperatif Komplikasyon Görülme Sıklı̆ı̆ Üzerine Etkisi: Retrospektif Çalışma

\section{GiRiş}

Anestezi uygulamalarında postoperatif dönemde, komplikasyonların erken tanısı, tedavisi için yakın takip kriterlerinin kullanımı önemlidir. Postoperatif komplikasyonların gelişiminden cerrahi girişimin türü, hastanın ASA grubu, operasyonun süresi, uygulanan anestezi yöntemleri sorumlu tutulmaktadır ${ }^{(1)}$. Hastaların fiziksel durum takibini kolaylaştırmak ve düzenli olmasını sağlanmak amacıyla skorlama yöntemleri geliştirilmiştir (2). Postanestezik dönemde üniform değerlendirme kriterleri sağlamak amacıyla genel anestezi, rejyonal anestezi veya sedasyon uygulanan tüm hastaların takibinde Post Anaesthetic Recovery (PAR) skoru, sonrasında geliştirilmiş Modifiye Aldrete Skoru (MAS) gibi skorlama sistemi (Tablo I) kullanılmaktadır ${ }^{(3)}$. Biz bu çalışmayla esas olarak uyandırma odasında skorlama sistemini kullanmanın, uyandırma odasında takip edilen hastalarda postoperatif komplikasyon gelişmesi üzerine etkisini retrospektif olarak göstermeyi amaçladık. Bununla beraber, elde edilecek veriler ile hasta yoğunluğu olan hizmet hastanelerinde hasta güvenliği açısından çıkarımlar elde etmeyi öngördük.

Tablo I. Modifiye Aldrete skorlama sistemi

\begin{tabular}{|c|c|c|}
\hline $\begin{array}{l}\text { Aktivite } \\
\text { (emirle veya } \\
\text { serbest } \\
\text { hareketle) }\end{array}$ & $\begin{array}{l}4 \text { ekstremite } \\
2 \text { ekstremite } \\
0 \text { ekstremite }\end{array}$ & $\begin{array}{l}2 \text { puan } \\
1 \text { puan } \\
0 \text { puan }\end{array}$ \\
\hline Solunum & $\begin{array}{l}\text { Derin soluk alabilme, rahat öksürebilme } \\
\text { Dispne, yüzeyel sınırlı soluk alabilme } \\
\text { Apneik }\end{array}$ & $\begin{array}{l}2 \text { puan } \\
1 \text { puan } \\
0 \text { puan }\end{array}$ \\
\hline Dolaşım & $\begin{array}{l}\text { Kan basıncı } \pm 20 \mathrm{mmHg} \text { preanestezik dönem } \\
\text { Kan basıncı } \pm 20-50 \mathrm{mmHg} \text { preanestezik } \\
\text { dönem } \\
\text { Kan basıncı } \pm 50 \mathrm{mmHg} \text { preanestezik dönem }\end{array}$ & $\begin{array}{l}2 \text { puan } \\
1 \text { puan } \\
0 \text { puan }\end{array}$ \\
\hline Şuur & $\begin{array}{l}\text { Tam uyanık } \\
\text { Seslenerek uyandırılıyor } \\
\text { Yanıt yok }\end{array}$ & $\begin{array}{l}2 \text { puan } \\
1 \text { puan } \\
0 \text { puan }\end{array}$ \\
\hline $\begin{array}{l}\mathrm{O}_{2} \\
\text { saturasyon }\end{array}$ & $\begin{array}{l}\text { Oda havasında }>\% 92 \\
\% 90 \mathrm{SpO}_{2} \text { için oksijen inhalasyonu gerekli } \\
\mathrm{O}_{2} \text { desteği ile }<\% 90\end{array}$ & $\begin{array}{l}2 \text { puan } \\
1 \text { puan } \\
0 \text { puan }\end{array}$ \\
\hline
\end{tabular}

(Hastaların derlenme odasından servise gönderilmeleri sırasında hazır olduklarının belirlenmesinde kullanılan skorlama sistemi) Aldrete Skoru 9 puana ulaștiğında hastalar derlenme odasından servise gönderilebilir.

\section{GEREÇ ve YÖNTEM}

Retrospektif olarak planlanan çalışmaya, Etik Kurul onayı (14.07.2016-230) alındıktan sonra başlandı.
Çalışmaya hastanemizde genel anestezi ve rejyonal anestezi (santral blok) ile ameliyat edilen toplam 800 hasta dosyası dahil edildi. Teknik nedenlerden dolayı her 2 gruptan birer hasta dosyası çalışmadan çıkarıldı. Dosyalar, anestezi kliniğinde farklı anestezi ve reanimasyon uzmanları tarafından takip edilen hastalardan, uyandırma odasında MASS ile takip edilen (MASG) ve edilmeyen grup (KG) olarak 2 grup olarak incelendi.

Anestezi uygulama türü, uyandırma odası ve servis kayıtları incelendi; uyandırma odası ve serviste postoperatif erken dönemde meydana gelen komplikasyonlar kaydedildi. Taramada 17 yaş altı ve yoğun bakıma entübe halde, sedatize gönderilen hastaların dosyaları çalışma dışı bırakıldı. Yoğun bakıma gönderilen hastalardan sedatize ve entübe olmayan, kooperasyon kurulabilen, uyandırma odasındaki takibi sırasında MASS değerlendirmesi yapılabilmiş olan hastaların dosyaları çalışmaya dahil edildi. Hastaların ASA skoru, cinsiyet, yaş, cerrahi işlem türü, anestezi yöntemi, preoperatif hemoglobin $(\mathrm{Hb})$ değerleri, ameliyat süreleri, uyandırma odasında kalış süreleri, kan transfüzyonu gereksinimi, analjezik gereksinimi, uyandırma odasında ve erken dönem serviste görülen komplikasyonlar kaydedildi.

Elde edilen verilerin analizinde, sürekli verilerin normal dağılıma uygun dağıııp dağılmadıkları ShapiroWilk testi ile incelendi. Sürekli değişkenler normal dağılım varsayımı sağlandığı durumda ortalama \pm standart sapma, sağlanmadığı durumda medyan değeri [\%25-\%75] şeklinde özetlendi. Kategorik değişkenler arasındaki ilişkiyi araştırmak amacıyla ki-kare testi kullanıldı. Kategorik değişkenler sayı ve yüzde cinsinden özetlenmiştir. İki bağımsız grup ortalaması karşılaştırılmasında normallik varsayımı sağlandığından Student t test kullanılmış olup, sağlanmadığı durumda Mann Whitney U testi kullanıldı. $p<0.05$ istatistiksel anlamlılık düzeyi olarak kabul edildi. İstatistik analizler için Statistica 13.3 programından yararlanıldı.

\section{BULGULAR}

Çalışmaya 798 hasta dosyası dahil edildi. Hastaların demografik verileri her 2 grupta benzerdi (Tablo II). Her 2 hasta grubu incelendiğinde ASA risk sınıflaması açısından gruplar arasında istatistiksel olarak 
anlamlı bir fark saptanmadı $(p=0.307)$. Major ve minör komplikasyonlar açısından her 2 grup arasında istatistiksel fark saptanmadı $(p=1.000)(p=0.794)$. Ameliyat öncesi konsültasyon istenmesi $(p=0.053)$, intraoperatif kan ürünü kullanımı $(p=0.268)$, analjezik uygulaması $(p=0.717)$ açısından gruplar arasında istatistiksel fark saptanmadı (Tablo II).

Anestezi şekli ile gruplar arasında istatistiksel olarak anlamlı bir ilişki görüldü $(p<0.001)$. MASG'da genel anestezi alanların oranı, KG'na göre anlamlı derecede daha fazla bulundu (Tablo II).

Uyandırma odasından sonra çıkış yeri olarak servis ve yoğun bakım irdelendiğinde 2 grup arasında istatistiksel olarak anlamlı bir fark vardı $(p=0.006)$. MASG'da yoğun bakıma çıkanların oranı KG'na göre anlamlı derecede daha fazla idi (Tablo II).

Tablo II. Demografik ve klinik özelliklere ait tanımlayıcı istatistikler

\begin{tabular}{|c|c|c|c|c|}
\hline & & GR & RUP & \\
\hline & & $\begin{array}{l}\text { MAS G } \\
(n=399)\end{array}$ & $\begin{array}{c}\text { Kontrol G } \\
(n=399)\end{array}$ & $\mathbf{p}$ \\
\hline ASA (n\%) & 1 & $212(53.3)$ & $210(52.6)$ & 0.307 \\
\hline & 2 & $139(34.9)$ & $146(36.6)$ & \\
\hline & 3 & $33(8.3)$ & $37(9.3)$ & \\
\hline & 4 & $14(3.5)$ & $6(1.5)$ & \\
\hline Anestezi Şekli (n\%) & RA & $42(10.5)$ & $81(20.4)$ & $<0.001^{*}$ \\
\hline & GA & $357(89.5)$ & $317(79.6)$ & \\
\hline Cinsiyet (n\%) & Erkek & $202(50.6)$ & $176(44.1)$ & 0.065 \\
\hline & Kadın & $197(49.4)$ & $223(55.9)$ & \\
\hline Yaş (yıl) & Yıl & $44.41 \pm 17.73$ & $46.18 \pm 18.56$ & 0.168 \\
\hline Major Komplikasyon & Yok & $398(100.0)$ & $398(99.7)$ & 1.000 \\
\hline & Var & $0(0.0)$ & $1(0.3)$ & \\
\hline Minör Komplikasyon & Yok & $391(98.0)$ & $392(98.2)$ & 0.794 \\
\hline$(n \%)$ & Var & $8(2.0)$ & $7(1.8)$ & \\
\hline Çıkış Yeri (n\%) & Servis & $359(90.2)$ & $381(95.5)$ & $0.006 *$ \\
\hline & YB & $39(9.8)$ & $18(4.5)$ & \\
\hline Konsultasyon (n\%) & Yok & $346(87.8)$ & $331(83.0)$ & 0.053 \\
\hline & Var & $48(12.2)$ & $68(17.0)$ & \\
\hline Kan ürünü kullanımı & Yok & $375(94.0)$ & $367(92.0)$ & 0.268 \\
\hline$(n \%)$ & Var & $24(6.0)$ & $32(8.0)$ & \\
\hline Analjezik Kullanımı & Yok & $73(18.3)$ & 77 (19.3) & 0.717 \\
\hline$(\mathrm{n} \%)$ & Var & $326(81.7)$ & $322(80.7)$ & \\
\hline
\end{tabular}

*Kategorik değişkenler n(\%) cinsinden özetlenmiştir.

*Normal dağılım gösteren sayısal değişkenler ortalama土standart sapma cinsinden özetlenmiştir.

RA; Rejyonal anestezi, GA; Genel anestezi, YB; Yoğun bakım, MAS $G$; Modifiye Aldrete Skor grubu
$\mathrm{Hb}$ değeri, uyandırma odasında kalma süresi ve ameliyat süresi değerleri incelenirken parametrik olmayan test kullanılmıştır (Tablo III). Hastaların uyandırma odasında kalış süreleri arasında istastistiksel olarak fark bulunmuştur $(p<0.001)$. Uyandırma odasında kalış süresi MASG'da $20 \mathrm{dk}$ (15-30 dk) iken KG'da 10 dk (0-15 dk) idi. Uyandırma odası kalış süresi medyanı MASG'da anlamlı derecede daha uzundu. Ameliyat süresi değerleri bakımından gruplar arasında istatistiksel olarak anlamlı bir farklılık yoktu $(p=0.070)$.

Hemoglobin değerleri bakımından gruplar arasında istatistiksel olarak anlamlı bir farklılık vardı ve KG preoperatif $\mathrm{Hb}$ değerleri medyanı anlamlı derecede daha yüksekti ( $p=0.001$ ) (Tablo III).

Major komplikasyonlar incelendiğinde KG'da bir hastada, kardiyopulmoner resusitasyon gerektiren kardiyak arrest gibi bir major komplikasyon görülmekle beraber, 2 grup arasında istatistiksel olarak anlamlı bir fark yoktu (Tablo II). Kontrol grubunda incelenen kayıtlarda benign prostat hiperplazisi nedeni ile spinal anestezi altında TUR-P operasyonu gerçekleştirilen hastada servise transfer sonrası ilk yarım saat içinde kardiyopulmoner resusitasyon gerektirecek kardiyopulmoner arrest geliştiği; kısa süreli ve yalnızca $1 \mathrm{mg}$ adrenalin (Ose ${ }^{\circledR}$ Adrenalin $0.5 \mathrm{mg}$ ampul) sonrası başarılı kardiyopulmoner resusitasyon ile kalp ritmi ve solunumu geri dönen hastanın reanimasyon yoğun bakımda takibine devam edildiği, sonrasında komplikasyon gelişmeyen hastanın 48 saat sonunda servise çıkarıldığı görüldü.

Tablo III. Laboratuvar ve klinik zamansal değişkenlere ait istatistikler

\begin{tabular}{lccc}
\hline & $\begin{array}{c}\text { MAS G } \\
\text { Medyan } \\
{[\% 25-\% 75]}\end{array}$ & $\begin{array}{c}\text { Kontrol G } \\
\text { Medyan } \\
{[\% 25-\% 75]}\end{array}$ & P \\
\hline Uyandırma odası & 20.00 & 10.00 & $<0.001^{*}$ \\
kalış süresi (dk) & {$[15.00-30.00]$} & {$[0.00-15.00]$} & \\
Ameliyat & 60,00 & 50.00 & 0.070 \\
süresi (dk) & {$[40.00-85.00]$} & {$[40.00-80.00]$} & \\
Hemoglobin & 12.80 & 13.50 & $0.001^{*}$ \\
$\left(\mathrm{~g} \mathrm{dL}^{-1}\right)$ & {$[11.90-14.30]$} & {$[12.00-15.10]$} & \\
\hline
\end{tabular}

*Normal dağılım göstermeyen sayısal değişkenler ise medyan [25\%-75\%] cinsinden özetlenmiştir. MAS G; Modifiye Aldrete Skor grubu

\section{TARTIŞMA}

Anesteziyi takiben postoperatif dönemde birçok sistemi içeren fizyolojik değişiklikler oluşur ve bu fizyo- 
H. Özmen ve ark., Uyandırma Odasında Hasta Takibinde Modifiye Alderete Skorlama Sistemi (MASS) ile Çalışmanın Postoperatif Komplikasyon Görülme Sıklı̆ı̆ Üzerine Etkisi: Retrospektif Çalışma

lojik değişikliklere bağlı çeşitli komplikasyonlar gözlenir. En sık karşılaşılan ve önemli sonuçları olan komplikasyonlar hemodinamik, solunumsal ve termoregülasyon kaynaklıdır ve bunlara genel anesteziden derlenmede gecikme, yetersiz nöromüsküler blok derlenmesi, hava yolu obstrüksiyonu, yetersiz gaz değişimi ve hemodinamik instabilite eşlik etmektedir ${ }^{(4-6)}$.

Literatürde komplikasyonların yarısının ilk 1 saatte, $\% 75^{\prime}$ inin ise ilk 5 saatte görülmekte olduğu ve bunların prognozunun perioperatif dönemdekilere göre daha kötü olduğu belirtilmektedir. Yüksek ASA değeri, acil cerrahi girişimler, 2-4 saat süren anestezi uygulamaları, abdominal ve ortopedik cerrahi girişimler en yüksek komplikasyon riskine sahiptir. Yapılan çeşitli çalışmalarda, uyanma odasında komplikasyon görülme sıklığı \%2.7-30 arasında değişmektedir (4-9). Bununla beraber, pek çok araştırmada komplikasyonlar arasında bulantı, kusma ve hipotermi de incelenmiş olmakla beraber, bizim de kullandığımız MAS skorlama sisteminde uyandırma odasında hipotermi ve ağrı sorgulaması yoktur. Ayrıca kliniğimizde rutin analjezik medikasyon uygulanmakta olup, uyandırma odasına gelen her hasta ISItıcı blanket ile ısıtılmaktadır.

Uyandırma odasında komplikasyonlara katkısı olabileceği düşünülebilecek postoperatif ağrıya yönelik olarak, postoperatif analjezik uygulanan hasta bakımından gruplar arasında fark görülmemiştir (326 hasta MASG, 322 hasta KG).

Çalışmamızda, postoperatif görülen komplikasyonları MASG'da \%2 ve KG'da \%2.1 olarak saptadık. Komplikasyonların her 2 grupta da hemen hepsi minör komplikasyonlar olup, yalnızca KG'da 1 hastada majör komplikasyon (kardiyak arrest) belirlendi. Yavaşcaoğlu ve ark.'nın ${ }^{(9)}$ çalışmasında, yaklaşık \%2.7 gibi bir anestezi sonrası komplikasyon rapor edilmiş, aynı çalışmada kardiyak arrest kaydedilen olguların 1 'i rejyonal anestezi uygulanan hasta iken, 6 'sı genel anestezi almış hasta olarak belirtilmiştir. Çalışmada, kardiyak arrest oranı \%0.017 olarak rapor edilmiştir. ASA 3-4 risk grubundaki hastalarda da anlamlı derecede kardiyak arrest oranı yüksek bulunmuştur. Çalışmamızda, MAS değerlendirme skoru kullanıımayan KG'da yer alan, ürolojik cerrahi geçirmiş, rejyonal anestezi almış bir olguda kardiyak arrest geliştiği rapor edildi. Hasta ASA 2 risk grubunda idi ve kardiyak arrest ile ASA riski arasında ilişki söz konusu değildi. Bu hastada MAS skoru ile takip yapılmadığı, servise gönderildikten sonra yarım saat içinde kardiyak arrestin geliştiği görüldü. Bizim çalışmamızda da, kardiyak arrest oranı \%0.12 olarak belirlenmiştir.

Pazar ve ark.'nın ${ }^{(10)}$ Anestezi Sonrası Bakım Ünitesinde (ASBÜ) Erken Uyarı Skorlama Sistemini (EUSS) kullandıkları randomize kontrollü çalışmada, skorlamanın kullanıldığı çalışma grubunda kontrol grubuna göre daha yüksek oranda (\%34.92 çalışma grubu, \%30.00 kontrol grubu) komplikasyon belirlendiği ve belirlenen komplikasyonlara da istatistiksel olarak anlamlı şekilde ilk $10 \mathrm{dk}$ içinde (\%95.45) müdahale edildiği gösterilmiştir. Yine aynı çalışmada, skorlamanın (EUSS) kullanıldığı kontrol grubunda, hastaların derlenme süreleri 52.46 $\pm 17.95 \mathrm{dk}$ olarak (aralık: 25-95 dk) bulunmuştur. Bu çalışmada, EUSS kullanan ve ASBÜ çalışan hemşirelerin bir kısmı hastaların skorlama nedeniyle ünitede kalış süresini uzun bulmuştur. Çalışma EUSS'nin hasta sonuçları üzerine olumlu etkisini göstermiştir.

Gören ve ark.'nın ${ }^{(8)}$ çalışmasında, hastaların derlenme odasında kalış süreleri, komplikasyonlu olgularda $45 \pm 19 \mathrm{dk}$, komplikasyonsuz olgularda $32 \pm 0.3 \mathrm{dk}$ olarak bulunmuş, yine postoperatif riskleri azaltmaya yönelik yapılmış hemşirelik takip çalışmalarında da komplikasyonlu vakalarda uyandırma odasında kalış süresinin uzadığı bildirilmiştir.

Çalışmamızda, ameliyat süreleri açısından her iki grup açısında istatistiksel olarak anlamlı bir fark yok iken (MASG: $60 \mathrm{dk}$, KG: $50 \mathrm{dk}$ ) hastaların uyandırma odasında kalış süreleri MASG'da KG'na göre istastistiksel olarak anlamlı ve daha uzun bulunmuştur. [MASG'da $20 \mathrm{dk}$ (15-30 dk), KG'da $10 \mathrm{dk}$ (0-15 dk)].

Bununla beraber, çalışmamızda preoperatif $\mathrm{Hb}$ değerleri KG'da (13.50 $\mathrm{g} \mathrm{dL}^{-1}$ ) MASG'a (12.80 $\mathrm{g} \mathrm{dL}^{-1}$ ) göre daha yüksek idi. Kan ürünü kullanımı değerlendirildiğinde MASG'da 24, KG'da 32 hastaya kan ürünü kulanıldığı görüldü. Bütün bu veriler MASG'da görece $\mathrm{Hb}$ düşüklüğünün görülen postoperatif komplikasyon oranını arttırmadığı görüldü. Bununla beraber, uyandırma odasından yoğun bakıma gönderilen hasta sayısı MASG'da anlamlı derecede daha fazla idi. MASG'da 39 (\%9.8) KG'da 18 (\%4.5) hastanın 
yoğun bakıma çıkarıldığı görüldü. Bu sonuçlar, skorlama sistemi kullanmanın, hastaların postoperatif nerede takip edileceğinde işaret edici olarak katkı sunduğunu da göstermektedir.

Jafar H. Faraj ve ark.'nın ${ }^{(6)} 1128$ hasta üzerinde yaptıkları çalışmalarında, derlenme odası komplikasyonu değerini \%4.25 oranında elde etmişler ve derlenme odasında özellikle iyi bir postoperatif bakım erken uyarı sistemleri ile uyanık çalışan sağlık personelinin bulunmasının önemine değinmişlerdir. Bu bize MASS güvenlik skorlaması gibi benzer takip prosedürleri ile postoperatif orta ve uzun vadede gelişebilecek komplikasyonların önünü almaya dair yakın monitörize hemşire bakımı kararının önemini bir kez daha vurgulamaktadır.

Kluger ve ark. ${ }^{(11)}$ preoperatif hazırlık, anestezi sonrası bakım ünitesinin altyapısı kadar burada çalışan eğitimli personelin yakın takibine dikkat çekmişlerdir.

Modifiye Aldrete skoru veya benzer skorlama sistemleri kullanılarak yapılan çalışmaların azığı çok açıktır. Anestezi sonrası ayılma odasında karşılaşılan komplikasyonları, zamanında belirlenip tedavisi yoluna gitmek ve beraberinde majör komplikasyonların önüne geçmek, sonuçta hastaların güvenle servise transferinin sağlanması, en az anestezi uygulaması kadar önemlidir. Yapılan bir dizi çalışmada, uyandırma odası ve hastanın buradan servise transferine kadar olan süreçte, olası komplikasyonları zamanında tespit edip erken müdahaleye zemin hazırlayan skorlama ve erken uyarı sistemlerini kullanma beraberinde hastaların servise transfer kriterlerinin de sınırlarını çizmiş olmaktadır $(8,10,12,13)$.

Yaptığımız retrospektif çalışmada da görüldüğü gibi; tıbbi uygulamalarda her aşamada hasta güvenliğinin olmazsa olmaz olduğu ve çok öncelendiği günümüzde, hastanın anestezi sonrası derlenme döneminde olası komplikasyonlarının zamanında belirlenip, tedavisini yaptıktan sonra servise, yatağına güvenle götürülmesinin yolu anestezi uyandırma odalarının gelişmiş donanımlı alt yapısı, eğitimli sağlık personeli ile çalışmak ve "Modifiye Aldrete Skorlama Sistemi" gibi algoritmaları kullanmaktan geçmektedir. Bu çalışma ile özellikle ülkemizde yoğun çalışılan devlet hizmet hastanelerinde hasta güvenliğini sağlamak açısından skorlama sistemlerinin kalite ölçeklerine girmesi ve kullanılmasının kaçınılmaz olduğunu vurgulamak isteriz.

Etik Kurul Onayı: T.C. Mersin Üniversitesi Rektörlüğü Klinik Araştırmalar Etik Kurul onayı alınmıştır (14.07.2016/230)

Çıkar Çatışması: Yoktur

Finansal Destek: Yoktur

Hasta Onamı: Retrospektif çalışma

Ethics Committee Approval: T. C. Mersin University Rectorate Clinical Research Ethics Committee approval was received (14.07.2016/230)

Conflict of Interest: None

Funding: None

Informed Consent: Retrospective study

\section{KAYNAKLAR}

1. Morgan GE Jr, Mikhail MS, Murray MJ. Post-anesthetic Care. Clinical Anesthesiology. $6^{\text {th }}$ ed. New York: McGraw-Hill; 2018;1257-75.

2. Türk Anesteziyoloji ve Reanimasyon Derneği. Postanestezik Bakım Kılavuzu (2005) - TARDWeb sitesi: https://www.tard.org.tr/assets/kilavuz/2.pdf

3. Aldrete JA, Kroulik D. A postanesthetic recovery score. Anesth Analg. 1970;49:924. https://doi.org/10.1213/00000539-197011000-00020

4. Kirdemir P, Alkaya Solmaz F. Postanesthesia recovery in general anesthesia. Türkiye Klinikleri J Anest ReanimSpecial Topics. 2013;6:82-90.

5. Rose DK, Cohen MM, De Boer DP. Cardiovascular events in the postanesthesia care unit: contribution of risk factors. Anesthesiology. 1996;84:772-81. PMID:8638830 https://doi.org/10.1097/00000542-199604000-00003

6. Faraj JH, Vegesna ARR, Mudali IN, et al. Survey and management of anaesthesia related complications in Pacu. Qatar Med J. 2012; 6470. https://doi.org/10.5339/qmj.2012.2.15

7. Wan Der Walt JH, Weeb RK, Osborne GA, Morgan C, Mackay P. Recovery room incidents in the first 2000 incident report. Anesth Intens Care. 1993;21:650. https://doi.org/10.1177/0310057X9302100527

8. Gören S, Özyurt G, Ercan İ. Derlenme odasında görülen komplikasyonlar ve ayılma skoru ile olan ilişkisi. Türk Anest. Rean. Cem. Mecmuası. 1999;27:297-301.

9. Yavaşcaoğlu B, Kaya F.N, Özcan B, et al. Erişkinlerde anestezi sonrası görülen komplikasyonların retrospektif değerlendirilmesi. Uludağ Üniversitesi Tıp Fakültesi Dergisi. 2009;35:73-78.

10. Pazar B, Yava A. Post-surgical operation care by application of an early warning scoring system and nursing guidan. Turk J Anaesth Reanim. 2013;41:216-22. https://doi.org/10.5152/TJAR.2013.37

11. Kluger MT. Recovery room incidents: a review of 419 reports from the Anaesthetic Incident Monitoring 
Study (AIMS). Anaesthesia. 2002;57:1060-6.

https://doi.org/10.1046/j.1365-2044.2002.02865.x

12. Phillips NM ,Street M, Kent B, Haesler E, Cadeddu M. Post-anaesthetic discharge scoring criteria: key findings from a systematic review. Int J Evid Based Healthc. 2013;11:275-84.

https://doi.org/10.1111/1744-1609.12044
13. Street M, Nicole M Phillips, Bridie Kent, Stephen Colgan and Mohammadreza Mohebbi. Minimising post-operative risk using a Post-Anaesthetic Care Tool (PACT): protocol for a prospective observational study and cost-effectiveness analysis. BMJ Open. 2015;5:e. https://doi.org/10.1136/bmjopen-2014-007200 